\title{
Mucinous Subtype in Patients With Colorectal Cancer
}

\author{
Hyung Jin Kim \\ Department of Surgery, St. Vincent's hospital, College of Medicine, The Catholic University of Korea, Suwon, Korea
}

\section{See Article on Page 57-63}

Colorectal cancer is not just one type of cancer. It represents a constellation of heterogeneous subtypes that result from different combinations of genetic events and epigenetic alterations. Chromosomal instability, microsatellite instability (MSI), and CpG island methylator phenotype have been identified as its 3 major molecular characteristics [1]. This may explain, at least partly, the differences in both the outcomes and the reactions to treatment. Recognition of these differences is important because it may influence the treatment decision [2]. Among its subtypes, MSI-high colorectal cancers have distinct clinical and pathological features, such as proximal location, early-stage (predominantly stage II), poor differentiation, mucinous histology and association with BRAF mutations [3].

A mucinous carcinoma is a distinct form of colorectal cancer and is characterized by abundant extracellular mucin that constitutes more than $50 \%$ of the tumor's volume [4]. It is the second largest histological subtype next to an adenocarcinoma and is found in $10 \%-15 \%$ of patients with colorectal cancer [5]. Although it is diagnosed based on histology, it can also be reliably identified with $\mathrm{T} 2$-weighted magnetic resonance imaging because of the presence of large, signal-intense mucin pools [6]. A mucinous carcinoma tends to occur in younger patients, is often seen in the proximal colon, is more often diagnosed at an advanced stage, and is more frequently associated with hereditary nonpolyposis colorectal cancer and inflammatory bowel disease [5]. The other things that should be considered is that positron-emission tomography/computed tomography is not helpful for patients with a mucinous carcinoma who have a low metabolic rate and that it cannot differentiate inflammation from cancer tissue.

Correspondence to: Hyung Jin Kim, M.D.

Department of Surgery, St. Vincent's hospital, College of Medicine, The

Catholic University of Korea, 93 Jungboo-daero, Paldal-gu, Suwon 16247, Korea

Tel: +82-31-249-8316, Fax: +82-31-247-5347, E-mail: hj@catholic.ac.kr

(C) 2017 The Korean Society of Coloproctology

This is an open-access article distributed under the terms of the Creative Commons Attribution NonCommercial License (http://creativecommons.org/licenses/by-nc/4.0) which permits unrestricted noncommercial use, distribution, and reproduction in any medium, provided the original work is properly cited.
Hosseini et al. [7] evaluated their experience treating patients with a mucinous carcinoma over a period of 14 years. The results in terms of incidence and clinicopathological factors were similar to those published in previously reported studies. Furthermore, in a univariate analysis, patients with a mucinous carcinoma showed poor disease-free survival and overall survival compared to patients with a nonmucinous subtype; however, in the multivariate analysis, those differences did not reach statistical significance. A mucinous carcinoma, in general, has long been considered as an unfavorable prognostic indicator; it has a very limited response to systemic therapy in the metastatic setting, probably due to the distinct pattern along which the tumor disseminates, and peritoneal spread is more common, although the mechanisms are unclear [8]. However, this has recently been disputed in various studies [2]. From this perspective, the importance of the location of the primary tumor has been highlighted. For a colonic mucinous carcinoma, there is no difference in overall survival after correction for stage [9]. However, for a rectal location, the results of a recent meta-analysis of patients with a mucinous rectal adenocarcinoma yielded a reduced rate of pathological complete response and tumor downstaging following neoadjuvant chemoradiotherapy, as well as an increased rate of positive resection margin and poorer overall survival following resection [10].

In conclusion, a mucinous carcinoma in the colorectum has several unique characteristics. Therefore, these characteristics should be considered during the treatment of a patient with a mucinous carcinoma, especially one in a rectal location, and with metastatic disease.

\section{CONFLICT OF INTEREST}

No potential conflict of interest relevant to this article was reported.

\section{REFERENCES}

1. Setaffy L, Langner C. Microsatellite instability in colorectal cancer: clinicopathological significance. Pol J Pathol 2015;66:203-18.

2. Nagtegaal ID, Hugen N. The increasing relevance of tumour histology in determining oncological outcomes in colorectal cancer. Curr Colorectal Cancer Rep 2015;11:259-66. 
3. Gelsomino F, Barbolini M, Spallanzani A, Pugliese G, Cascinu S. The evolving role of microsatellite instability in colorectal cancer: A review. Cancer Treat Rev 2016;51:19-26.

4. Symonds DA, Vickery AL. Mucinous carcinoma of the colon and rectum. Cancer 1976;37:1891-900.

5. Hugen N, Brown G, Glynne-Jones R, de Wilt JH, Nagtegaal ID. Advances in the care of patients with mucinous colorectal cancer. Nat Rev Clin Oncol 2016;13:361-9.

6. Kim MJ, Park JS, Park SI, Kim NK, Kim JH, Moon HJ, et al. Accuracy in differentiation of mucinous and nonmucinous rectal carcinoma on MR imaging. J Comput Assist Tomogr 2003;27:48-55.

7. Hosseini S, Bananzadeh AM, Salek R, Zare-Bandamiri M, Kermani AT, Mohammadianpanah M. Prognostic significance of mucinous histologic subtype on oncologic outcomes in patients with colorectal cancer. Ann Coloproctol 2017;33:57-63.

8. Hugen N, van de Velde CJ, de Wilt JH, Nagtegaal ID. Metastatic pattern in colorectal cancer is strongly influenced by histological subtype. Ann Oncol 2014;25:651-7.

9. Hyngstrom JR, Hu CY, Xing Y, You YN, Feig BW, Skibber JM, et al. Clinicopathology and outcomes for mucinous and signet ring colorectal adenocarcinoma: analysis from the National Cancer Data Base. Ann Surg Oncol 2012;19:2814-21.

10. McCawley N, Clancy C, O’Neill BD, Deasy J, McNamara DA, Burke JP. Mucinous rectal adenocarcinoma is associated with a poor response to neoadjuvant chemoradiotherapy: a systematic review and meta-analysis. Dis Colon Rectum 2016;59:1200-8. 